\title{
Desenvolvimento sustentável: governança, participação e parcerias intersetoriais $^{1}$
}

\section{Sustainable develo pment: governance, participation and intersectoral partnerships}

\author{
Yasmine Santos Mansur ${ }^{\mathrm{a}}$ \\ Danusa Dias Reis Coutinhob
}

Armindo dos Santos de Sousa Teodósio ${ }^{\mathrm{C}}$

${ }^{a}$ Doutora pela Pontifícia Universidade Católica de Minas Gerais. E-mail: yasmine.mansur@gmail.com

${ }^{\mathrm{b}}$ Mestre em Administração/ PUC Minas.

E-mail: danusadrcoutinho@gmail.com

'Doutorado em Administração de Empresas, e Professor Adjunto IV da Pontifícia Universidade Católica de Minas Gerais, Brasil. E-mail: armindo.teodosio@gmail.com

Recebido em: 12/10/2016 I Aceito em: 02/12/2016

\footnotetext{
${ }^{1}$ Esse artigo foi apresentado na Décima Conferencia Regional de ISTR para América Latina y el Caribe que aconteceu emSan Juan - Ponce, Puerto Rico - 5 a 7 de agosto de 2015.
} 


\title{
RESUMO
}

Considerando a complexidade do mundo globalizado, a interdependência das relações humanas e os desafios sociais e econômicos comuns, este ensaio teórico pretende construir um framework, sobre as bases do desenvolvimento sustentável, trazendo os conceitos, que acreditamos ser de suma importância para o alcance do mesmo. Neste artigo, discutimos a emergência e os desafios de entender o desenvolvimento sustentável em seus três núcleos fundamentais: a governança territorial, a participação social e as parcerias intersetoriais. Nessa perspectiva, o presente ensaio tem por objetivos a descrição desses, bem como identificar as oportunidades e desafios que tais práticas colaborativas agregam à pretensão de um desenvolvimento que de fato seja sustentável. Buscou-se clarificar um pouco mais as questões referentes à governança e participação como elementos relevantes para a prática dos projetos e parcerias em prol do desenvolvimento dos territórios, evidenciando pontos críticos para o sucesso destas práticas. O artigo está composto por cinco seções distintas: a primeira trata-se da introdução ao tema; na segunda parte são discutidos os conceitos referentes à governança territorial; na terceira seção foi realizada uma análise a respeito dos desafios da participação; a quarta seção traz uma reflexão quanto aos desafios das parcerias intersetoriais; e a quinta seção apresenta as considerações finais a respeito do tema.

Palavras-Chave: Desenvolvimento Sustentável. Governança. Participação. Intersetorialidade.

\begin{abstract}
Considering the globalized world, the interdependence of human relations and the common social and economic challenges, this theoretical essay aims to build a framework on the basis of sustainable development, bringing the concepts that we believe is of paramount importance to achieve it. In this article, we discuss the emergence and challenges to understand sustainable development in its three fundamental cores: territorial governance, social participation and intersectoral partnerships. In this perspective, this paper aims the description of these cores, as well as to identify the opportunities and challenges that such collaborative practices add to the pretense of a development that is, in fact, sustainable. Weattempted to clarify the issues of governance and participation as elements relevant to practical projects and partnerships for the development of territories, highlighting critical points to the success of these practices. The article is composed of five distinct sections: the first one it is the introduction to the subject; the second part discusses the concepts related to territorial governance;in the third section was performed an analysis on the challenges of participation; the fourth section bringsa reflection on the challenges of intersectoral partnerships;and the fifth section presents the final remarks on the subject.
\end{abstract}

Key words: Sustantável Development. Governance. Participation. Intersectoriality 


\section{INTRODUÇÃO}

O século $X X$ foi palco de debates sobre formas efetivas de reduzir a pobreza e promover o desenvolvimento sustentável e a justiça social. Na busca por novos caminhos alguns consensos emergiram, dentre eles a necessidade de ações mais colaborativas e integradoras. As discussões atentam para o papel catalizador e facilitador do Estado, mas ressaltam que este não deve ser o provedor único das soluções.

No contexto histórico, as políticas e programas sociais têm demonstrado uma desconexão entre o foco dos investimentos sociais e as reais necessidades e valores das comunidades, principalmente daquelas mais vulneráveis; o que claramente denota o anseio por mudanças estruturais dessas políticas, para formas mais participativas e compartilhadas de formulação e implementação de ações sociais e de projetos que promovam um desenvolvimento mais sustentável. Diante deste cenário o conceito de governança emerge e se associa a outros dois, o de participação e o de parcerias intersetoriais.

Nesse artigo, discutimos os conceitos de governança, participação social e parcerias intersetoriais, que são fundamentais para o entendimento da ampliação do desenvolvimento sustentável. Entendemos que a conjunção desses conceitos ajudam a construir respostas para problemas sociais concretos.

Sob esta perspectiva, este trabalho pretende contribuir para o debate através da constituição de um framework que norteie pesquisas que anseiam por respostas a perguntas como estas: Qual o papel da sociedade civil na construção de parcerias intersetoriais para a governança do desenvolvimento sustentável? Como promover a participação e a cooperação na governança social em territórios marcados pela presença de atores com múltiplos interesses e alta desigualdade?

Pretende-se contribuir para essas respostas a partir de reflexões sobre os desafios da articulação de novos atores nos processos de desenvolvimento, discutindo as dimensões da governança dos territórios, perspectivas e armadilhas da participação popular. Busca-se ainda compreender como os processos de parcerias intersetoriais promovem o desenvolvimento sustentável dos territórios. 


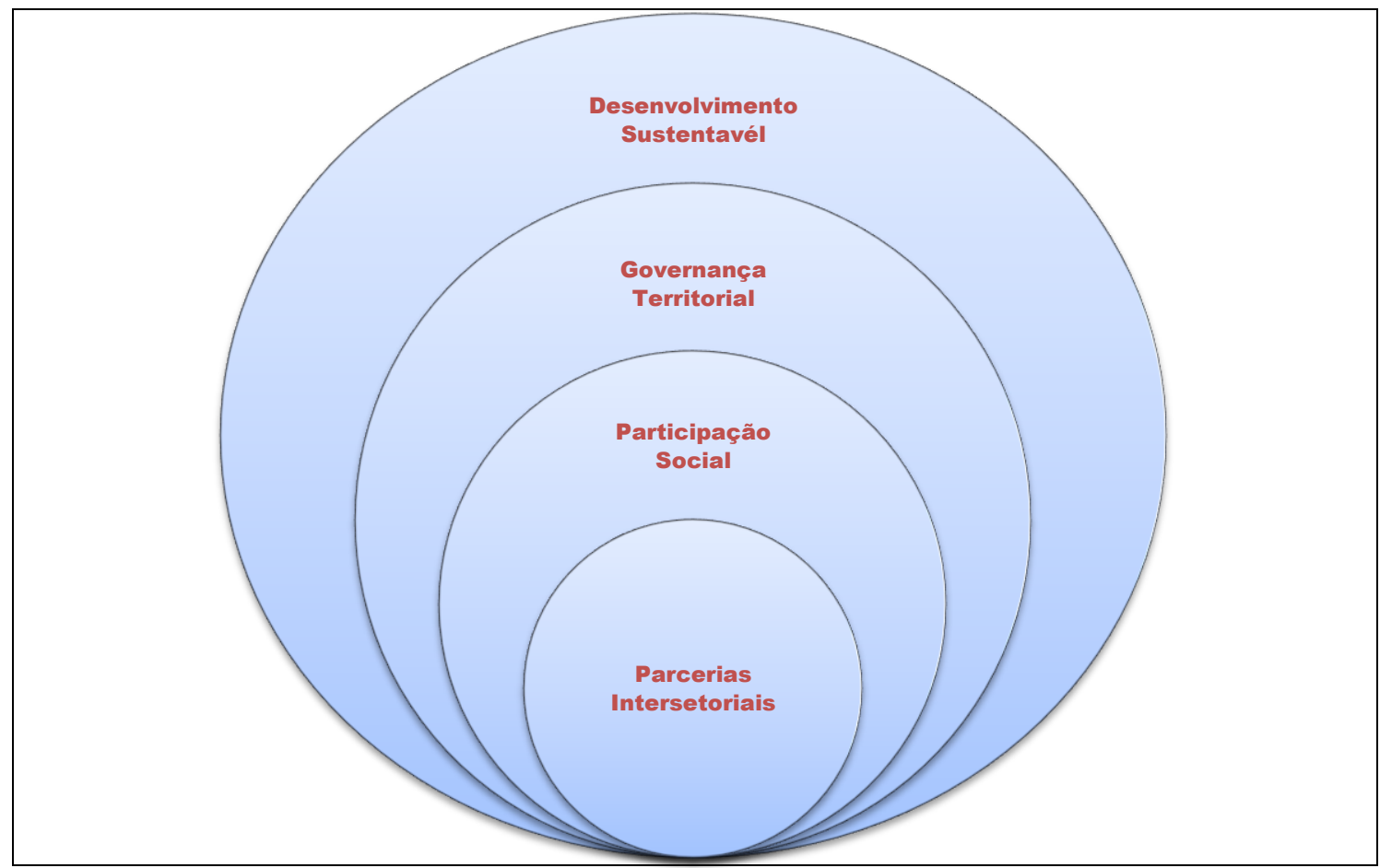

Figura 1: Fatores para a promoção do Desenvolvimento Sustentável. Fonte: Elaborado pelos autores.

Nesse sentido entendemos que o desenvolvimento sustentável deve ser analisado a partir de uma perspectiva que envolva esses conceitos, tais como a Figura 1 apresenta, ou seja, o desenvolvimento sustentável, para que ocorra de forma plena, necessita de uma governança capaz de promover a participação social e fomentar parcerias intersetoriais.

\section{AMPLIAÇÃO DA PARTICIPAÇÃO SOCIAL E GOVERNANÇA}

A ampliação da participação social está relacionada com as estruturas de gestão e governança territorial. Algumas abordagens nas áreas das ciências sociais apontam para um tipo de governança que busque a participação social, salientando o papel dos cidadãos na colaboração do processo sócio-político, desde a identificação dos problemas até a avaliação dos resultados (TENÓRIO, 2004). Segundo Fischer (2002), a ideia que dá significado e caracteriza uma 'boa gestão' é a de governança. A noção de boa governança vem intrinsecamente associada à capacidade governativa, passando a ser requisito indispensável para um desenvolvimento sustentável, na medida em que permitiria a incorporação ao 
crescimento econômico das dimensões da equidade social e da promoção dos direitos humanos (COSTA, 2008). Em suma, governança não é apenas uma tarefa do Estado, mas também a maneira pela qual a sociedade reconhece e lida com seus problemas, usando o governo como uma ferramenta e um parceiro.

Originalmente, o termo governança foi utilizado na década de 1930, em análises no âmbito das empresas. A partir da década de 1970, a expressão foi utilizada no âmbito de governo, para tratar de análises da capacidade de governabilidade e gestão de recursos públicos (CANÇADOet al., 2013). Porém "na última década do século $X X$, a abordagem ampliou-se ainda mais, passando a ser focalizada tanto na capacidade do Estado quanto da iniciativa privada e da sociedade civil como atores do desenvolvimento" (CANÇADOet al., 2013, p. 324). A governança enfatizada pela natureza democrática, abrange os "mecanismos de participação, de formação de compromissos ou pactos e de envolvimento da sociedade civil no processo de desenvolvimento" (CANÇADOet al., 2013, p. 325).

Historicamente, o termo governança foi resgatado no final da década de 1980 pelas agências internacionais de auxílio ao desenvolvimento ligadas ao Banco Mundial (CARRION; BAUER, 2011). A governança pode ser considerada um termo plural, que "compreende não apenas a substância da gestão, mas a relação entre os agentes envolvidos, a construção de espaços de negociação e os vários papéis desempenhados pelos agentes do processo" (TENÓRIO, 2004, p. 2).

Pimentel e Pimentel (2010) sugerem que a governança seja também tratada como governança territorial e enfatizam a importância da ação coletiva como uma estratégia de articulação dos atores sociais, alinhada com princípios participativos e democráticos. A governança territorial, segundo os autores, pode ser vista como uma forma de provocar os atores sob a ótica do espaço em que atuam e vivem a se articular para gerenciar coletivamente os bens públicos (PIMENTEL; PIMENTEL, 2010). Ao se adotar o termo governança territorial não se está considerando somente os atores que atuam ou residem num determinado território e sim "os atores com poder de intervenção no território, oriundos de outras escalas territoriais, que intervêm no processo de desenvolvimento e construção do espaço local" (CANÇADOet al., 2013, p. 332). Essas formas mais colaborativas de construção das 
iniciativas sociais, traz benefícios para todas as partes envolvidas, Darà comunidade a oportunidade de aprender e refletir com o conhecimento e a experiência dos outros, pode fortalecer o capital social entre instituições, comunidades e indivíduos.

Assim, a discussão sobre governança remete à reflexão sobre as perspectivas de ação coletiva, buscando romper as fronteiras da vida privada para promover o bem comum. Trata-se de uma "categoria analítica, associada a conceitos como participação, parceria, aprendizagem coletiva, regulação, sinônimo de 'bom governo', enfim, um guarda-chuva para as boas práticas [...] de desenvolvimento local e regional" (FISCHER, 2002, p. 26).

Quando se trata de governança, refere-se a uma forma compartilhada de governo e/ou gestão como uma nova arquitetura de articulações sociais, que pode ser associada às parcerias de diversos tipos: convênios entre diversas instituições, consórcios intermunicipais, acordos, contratos ou até simplesmente um espaço informal de articulação. O fato é que o ponto chave de renovação da governança seria a decisão conjunta e participativa de atores que, até então, agiam isoladamente (DOWBOR, 2002). A governança compartilhada é interpretada, neste estudo, como um fenômeno capaz de gerar uma gestão social pautada pelo diálogo entre os diferentes atores representantes das três esferas da sociedade (Estado, empresas privadas e sociedade civil), ou seja,a gorvernança territorial plena, indica que a parceria efetiva entre o Estado, a sociedade civil e o setor privado revela que esses são co-responsáveis pela promoção do bem-estar social.

Experiências pelo mundo têm mostrado que até mesmo o interesse privado opera melhor e pode ser garantido quando se fortalece o interesse público, tomando-se os interesses democráticos e coletivos como base para 0 desenvolvimento integrado do território (SACHS, LOPES; DOWBOR, 2010). Conforme o relatório mundial sobre o setor público, elaborado pelas Nações Unidas em 2005 (apud, está em gestação uma evolução de uma visão tradicional da administração pública para uma visão contemporânea (Tabela 2), que o relatório chama de governança participativa ou responsive governance (SACHS, LOPES; DOWBOR; 2010).

A responsive governance, que traduzimos aqui por governança participativa, está baseada numa proposta mais pública, onde as 
chefias escutam melhor o cidadão, e onde é a participação cidadã, através de processos mais democráticos, que assegura que os administradores sejam mais eficientes, [...] mais afinados com o que deles se deseja. É a diferença entre a eficiência autoritária por cima, e a eficiência democrática pela base. A eficiência é medida não só no resultado, mas no processo. (SACHS, LOPES; DOWBOR, 2010, p. 10).

No Quadro 1, são apresentadas diferentes abordagens orientadoras da gestão pública, com suas implicações para a governança e a relação estabelecida entre Estado e sociedade.

\section{Quadro 1 - Evolução da noção de governo}

\begin{tabular}{|c|c|l|l|}
\hline & $\begin{array}{l}\text { Administração } \\
\text { Pública }\end{array}$ & $\begin{array}{l}\text { Nova } \\
\text { Gestão Pública }\end{array}$ & $\begin{array}{l}\text { Governança } \\
\text { Participativa }\end{array}$ \\
\hline $\begin{array}{c}\text { Relação } \\
\text { Cidadão-Estado }\end{array}$ & Obediência & Credenciamento & Empoderamento \\
\hline $\begin{array}{c}\text { Responsabilidade } \\
\text { da Administração } \\
\text { Superior }\end{array}$ & Políticos & Clientes & Cidadãos, atores \\
\hline $\begin{array}{c}\text { Princípios } \\
\text { Orientadores }\end{array}$ & $\begin{array}{c}\text { Cumprimento } \\
\text { de leis e regras }\end{array}$ & $\begin{array}{c}\text { Eficiência e } \\
\text { resultados }\end{array}$ & $\begin{array}{c}\text { Responsabilidade, } \\
\text { transparência e } \\
\text { participação }\end{array}$ \\
\hline $\begin{array}{c}\text { Critério para } \\
\text { Sucesso }\end{array}$ & $\begin{array}{c}\text { Objetivos } \\
\text { quantitativos }\end{array}$ & $\begin{array}{c}\text { Objetivos } \\
\text { qualitativos }\end{array}$ & Processo \\
\hline Atributo Chave & Imparcialidade & Profissionalismo & Participação \\
\hline
\end{tabular}

Fonte: UN, World Public Sector Report (2005 apud SACHS, LOPES; DOWBOR, 2010, p. 10).

$\mathrm{Na}$ definição dos rumos do desenvolvimento do território, pressupõe-se que deve haver um estímulo para a participação e articulação de relações intersetoriais de diálogo, de forma a canalizar a participação dos atores em espaços públicos, como fóruns, conselhos e assembleias, e influenciar as dinâmicas sociais para que se complementem e se reforcem mutuamente. A partir daí, a governança participativa pode acontecer nos espaços nos quais haveria uma convergência mínima de interesses para a tomada de decisão, garantindo que a participação não se circunscreva ao âmbito de um determinado projeto. Trata-se, pois, de: 
[...] uma evolução que busca a construção de uma capacidade real de resolução de problemas através das pactuações necessárias com a sociedade, pois realmente existente. Esta sistematização de tendências mundiais vem dar maior credibilidade aos que lutam pela reapropriação das políticas pela cidadania, na base da sociedade, em vez da troca de uma solução autoritária por outra. (SACHS, LOPES; DOWBOR, 2010, p. 11).

A participação pressupõe a realização de ações coletivas, e isso exigiria, de uma forma ou de outra, que os participantes dessa ação sejam induzidos a cooperar (FLIGSTEIN, 2007, p. 62). Isto porque, segundo Dowbor (2002, p. 49) "não se trata mais de derrotar os outros, de obter sucesso à custa dos outros, mas de somar o máximo de proveitos para o conjunto".

De acordo com Fligstein (2007), ao se concentrar na construção de ordens sociais locais, a teoria dos campos se propõe analisar a maneira como grupos específicos chegam a definir um domínio social. Assim, poderia oferecer uma visão de como as ordens locais serão criadas, sustentadas e transformadas. Conforme esse mesmo autor, os "campos se referem a situações nas quais grupos organizados de atores se reúnem e desenvolvem suas ações recíprocas face a face" (FLIGSTEIN, 2007, p. 65), sendo influenciados pela ação cultural de três maneiras: (i) pelas práticas sociais preexistentes; (ii) pelo 'conhecimento local' imerso nas relações de poder entre os grupos; e (iii) pelas estruturas cognitivas, "semelhantes ao que Bourdieu chama de habitus, para analisar os significados das ações dos outros" (FLIGSTEIN, 2007, p. 64).

Fligstein (2007) estabelece uma conexão entre a teoria dos campos de Bourdieu e a teoria da habilidade social, oferecendo um constructo teórico relevante para a análise de parcerias intersetoriais. Na medida em que a vida social se constrói e reconstrói, o processo emerge e as identidades, os interesses e as ações podem ser consolidados. Para que isso aconteça, Fligstein (2007) adota o pressuposto de que todos os seres humanos detém alguma habilidade social quando atuam em grupo.

O caso de Quebec, no Canadá, se destacaria por conta de seu modelo de desenvolvimento sustentável com envolvimento colaborativo de multi-atores, na construção de uma realidade social. O modelo é conhecido como o Quebec Model e se caracteriza pela participação de uma pluralidade de agentes e pela hibridização 
por meio de um arranjo econômico e social de empresas privadas, públicas e baseadas em empresas cooperativas e sociais com diversas formas de governança em uma ação cidadã (LÉVESQUE et al., 2012).

Estes experimentos resultaram em uma relativa convergência de três esferas sócio-econômicas: o privado, o público e os setores sociais. Conduzida às vezes pelo governo, às vezes por parte dos empregadores e às vezes por organizações de base da sociedade civil, essa convergência contribuiu para a implementação de um modo baseado em parceria de governança. (LÉVESQUE et al., 2012, p. 11).

Por meio de diferentes 'fórmulas de cooperação', a ação cidadã em Quebec começou quando os cidadãos tomaram a iniciativa da criação de serviços, ao invés de simplesmente fornecê-los, permitindo que as alianças entre os usuários dos serviços e os profissionais de cada especificidade se reconfigurasse nas relações de produção e consumo. Essa estratégia provocou um realinhamento das ações de cidadania e despertou um sentido ativista da sociedade civil para o enfretamento das demandas sociais (LÉVESQUE et al., 2012). Os atores desse processo são pessoas ligadas aos movimentos sociais (grupos de mulheres, grupos comunitários, grupos ambientalistas), aos sindicatos, à administração pública e representantes das comunidades locais.

A partir da implementação da capacidade de agir e participar da tomada de decisão sobre situações específicas no contexto público e social de Quebec, duas modalidades de trajetórias de movimento social surgiram e, mais tarde, convergiram em torno do desenvolvimento sustentável. Tais trajetórias foram o 'movimento regional' e 'movimento urbano', considerados pelos autores como um exemplo de inovação social (LÉVESQUE et al., 2012).

Os principais resultados dessa mobilização em Quebec consistiram no desenvolvimento de uma estratégia, definida como Economic Community Development, e na criação de uma organização dedicada a aplicá-la em outras regiões: a Corporations de Développement Économique Communautaire (CDEC) (LÉVESQUE et al., 2012). Os objetivos das CDEC's são: (i) promover a colaboração entre os atores em um bairro; (ii) colaborar para o lançamento de projetos de desenvolvimento baseados em parcerias; e (iii) apoiar o empreendedorismo local, para facilitar a criação de empregos e promover a empregabilidade e qualificação 
aos desempregados, visando reintegrá-los no mercado de trabalho em menor tempo possível. Essa estratégia repercutiu em diversos debates, resultando em grande mudança na ação comunitária.

A inovação social realizada a partir do Quebec Model destacou-se por três motivos: (i) pela governança, ou seja, o progresso em termos de consulta, cooperação, parceria, reconhecimento das partes interessadas, democracia deliberativa e democracia direta; (ii) pela (co)construção de políticas públicas, que se refere à participação de atores, especialmente dos movimentos sociais, e ao desenvolvimento de políticas públicas; e (iii) pelas contribuições de diversos atores para a pluralidade de formas de economia (economia privada, economia pública e economia social), além das inter-relações e parcerias entre tais setores econômicos (LÉVESQUE et al., 2012).

$\mathrm{Na}$ evolução dos processos de inovação social consolidados em Quebec foram encontrados alguns 'gatilhos', que provocaram a mudança de postura da sociedade, como a crise de confiança no sistema. Essa experiência reforça, teoricamente, a importância da participação ativa da sociedade civil para a construção, evolução e consolidação das parcerias intersetoriais, visando o desenvolvimento sustentável.

No entanto, apesar do exemplo bem sucedido de Quebec, é preciso estar atento para as armadilhas que alguns processos participativos podem apresentar, para tanto na próxima seção nos dedicamos a esclarecer o debate sobre a participação popular.

\section{DIMENSÕES DA PARTICIPAÇÃO POPULAR}

O tema da participação popular no desenvolvimento traz em seu cerne a disposição das pessoas para se conectar umas às outras e cooperar, característica esta essencial à sociedade humana e também para o bom andamento das intervenções que buscam promover o desenvolvimento de territórios marcados pelos problemas sociais e ambientais. Entretanto, não se pode dizer que é assim em todos os casos em que ocorre, sendo que algumas formas de participação podem acabar por se constituir em dinâmicas particularmente excludentes (CORNWALL, 2002). 
Para entender a participação é necessário analisar o desenvolvimento sustentável a partir de uma perspectiva territorial. Nesse caso, a participação pode se constituir em um processo positivo para o avanço da democracia, da equidade social e da própria sustentabilidade.

De acordo com Santos (2005) a participação popular emerge em contextos contemporâneos de crise de legitimidade ou de governabilidade. Está inserida em múltiplos domínios da vida social, envolvendo diferentes atores e muitas vezes opera sobre uma realidade social marcada pela grande heterogeneidade de interesses (BACHTINGER et al,2010; ELSTUB, 2010). A partir daí vem assumindo cada vez mais importância na atualidade à medida que o envolvimento dos cidadãos nos processos de decisão se torna uma realidade e é entendido por diferentes atores como um direito e uma pré-condição para o bom andamento das propostas de intervenção visando o desenvolvimento (MATOS, 2011).

Como um processo ativoe em constante mudança, a participação popular possui limitações impostas pela sua própria dinâmica, que resulta das relações de poder que se estabelecem em realidades sociais diversas. Tanto a participação quanto a não participação refletem interesses e relações de poder, que reproduzem a subordinação ou a luta de um grupo para romper com as dinâmicas de dominação (WHITE, 2000). Reconhecendo que a participação popular é um processo político, é importante entenderalguns aspectos importantes para saber quem está envolvido, em quais termos e com quais objetivos pretendem participar. Ao considerar a reprodução de relações de poder já estabelecidas, será possível analisaraté que ponto o processo participativo se institui como desafiador (ou não) dos padrões dominantes.

A participação popular possui um alto grau de complexidade quando requerida e exercida no contexto do desequilíbrio social, político e econômico do mundo global. Dessa forma, para o enfrentamento dos desafios de uma realidade social, o problema da participação popular nos sistemas políticos aparece na análise das instituições sociais e se revela nas dificuldades do uso da liberdade política.

No âmbito da democracia que habitam os ciclos de desenvolvimento e seus programas, é preciso estar atento para o fato de que ter elementos de participação 
não implica em compartilhar poder. Participação popular efetiva, pressupõe uma estrutura institucional que, articule os cidadãos, promova um debate público pautado no bem comum e propicie a construção dos interesses e identidades para tal objetivo, garantindo as condições formais necessárias para que se consolide (LÜCHMANN, 2002).

No decorrer do processo é preciso considerar que nem sempre a participação traz resultados positivos para ofortalecimento da democracia e da cidadania ou ampliação da esfera pública e aprimoramento da gestão de políticas e programas. As OSCs (Organizações da Sociedade Civil) se constituem como atores importantes nesse processo por serem consideradas capazes de fornecer incentivo e apoio a iniciativas locais. As OSC's se caracterizam como organizações formadas por membros da sociedade civil com a intenção de atuar junto a sociedade e o Estado visando o desenvolvimento socioeconômico e o fortalecimento da cidadania (Oliveira \& Junqueira, 2003).Nesse cenário, devemos atentar para alguns fatoresapontados por Milani (2003), que podem ser considerados comopontosque corrompem a promoção da participação e o sucesso dos projetos de desenvolvimento sustentável. Tais como:

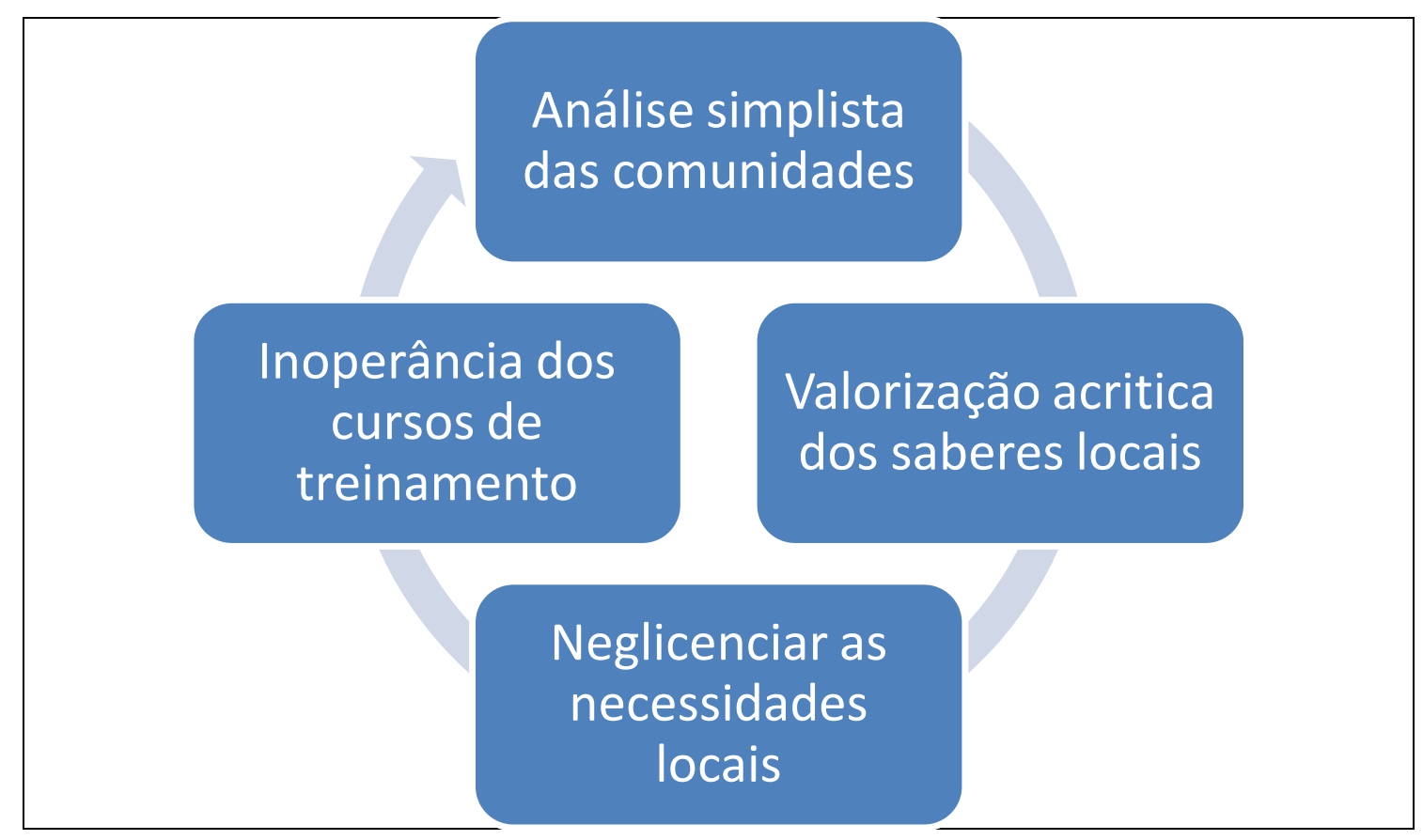

Figura 2: Ciclo de fatores dificultadores da participação.

Fonte: Elaborada pelos autores, com base em Milani (2003). 
Muitas vezes os órgãos que promovem os projetos, analisam as comunidades de maneira simplista, o que pode resultar na falha do projetouma vez que entendem as comunidades como homogêneas, estáticas e harmônicas. Como consequência, pode haver uma valorização acrítica dos saberes tradicionais, que muitas vezes leva a negligência das relações de micro poder entre os indivíduos de uma comunidade.Esse movimento pode provocar o uso indiscriminado da expressão empowerment (empoderamento), que muitas vezes conduz os projetos de forma a negligenciar as necessidades locais, fixando-se demasiadamente na eficiência administrativa. E a inoperância e a ingenuidade passam a cercar os cursos de treinamento oferecidos pelas agências de cooperação, governos e OSC (Organizações da Sociedade Civil), acabando por levar esses atores a esperar que, em poucos dias de treinamentos intensivos, os indivíduos saiam dali sensibilizados e conscientes da realidade social em que vivem, ou em que irão atuar.A análise desse ciclo de fatores dificultadores da participação nos aponta para a necessidade de luta por autonomia e espaços de participação política nos limites de cada instituição (GOHN, 2003).

É importante reconhecer asOSC's como um espaço de interação de atores com uma pluralidade de interesses e divisão de poder (ALVES, 2006). Portanto, em conjunto com a diversidade de atores que integram a sociedade local, vislumbra-se a necessidade de cada comunidade "traçar estratégias que fortaleçam suas capacidades na solução dos problemas" (TENÓRIO, 2004, p. 17), indo ao encontro do que desejam para seu desenvolvimento, com a garantia de ampla participação dos diferentes atores sociais de determinado território, seja no nível local ou mesmo regional (ROVER apud BROSE, 2001).

Apesar dos riscos e das armadilhas, a participação popular pode se constituir em um mecanismo que aproxime a sociedade do Estado em prol do desenvolvimento, à medida que aprofunda o diálogo entre diferentes atores. As diferentes perspectivas de descentralização e de reordenamento das políticas de desenvolvimento, conjugadas a uma aproximação da sociedade civil a partir de lógicas menos tradicionais (não clientelistas, assistencialistas, paternalistas e marcadas pelo nepotismo) a participação e o engajamento dos cidadãos tornam-se 
centrais, uma vez que são considerados como um mecanismo essencial de contribuição para democratização do processo de tomada de decisão.

As OSCs também podem assumir papel importante no controle, regulação e legitimação das ações do Estado frente aos diversos projetos de desenvolvimento e frente a sociedade de maneira geral. Podem desenvolver uma relação com o Estado pautada pelo enfrentamento, oposição e controle social em bases conflitivas, pelo adovacy e pela defesa de direitos e/ou ainda parceria e complementariedade no ciclo de políticas públicas (TEODÓSIO, 2008).

As relações fruto da interação dos atores da sociedade civil, Estado e mercado ocorrem no campo das políticas, que por si se dão em um processo dialético e dialógico, que prima pela persuasão e conciliação de interesses ou pelo acirramento dos conflitos. Desse modo, a política é vista como uma instância da vida em sociedade que se constitui a partir de relações sociais e econômicas e que também pode moldá-las ou influenciá-las, servindo de esteio ou base para as ações e relações das OSCs na cooperação para o desenvolvimento ou em políticas públicas.

No que diz respeito aos benefícios econômico-sociais dos processos participativos, seja através de políticas públicas ou de projetos das OSCs, um dos principais é a possibilidade da inversão de prioridade do Estado, colocando os interesses da sociedade em primeiro lugar. A intenção seria a de que o diagnóstico das necessidades fosse debatido com a comunidade, traduzindo-se em políticas públicas que agreguem desenvolvimento às comunidades. Uma das possibilidades para que se alcance esses benefícios é o fomento das parcerias intersetoriais como agentes de desenvolvimento.Na seção seguinte trabalharemos esse aspecto.

\section{PARCERIAS INTERSETORIAIS COMO AGENTES DO DESENVOLVIMENTO SUSTENTÁVEL}

No presente artigo, consideramos como o desenvolvimento sustentável algo que possa ser capaz de fomentar dentro de um mesmo território atividades que promovam oportunidades economicamente rentáveis, ambientalmente responsáveis e socialmente justas (SACHS, 2004; DOWBOR, 2002). Precisa ainda dar conta de Ciência e Sustentabilidade - CeS / Juazeiro do Norte v. 2, n. 2, p. 28-50, jul/dez 2016 
contribuir para o estabelecimento de diálogos, ao invés de imposições, entre atores da esfera governamental, em todos os seus níveis, da sociedade civil e, também, dos mercados, de forma estabelecer e efetivar a cooperação entre os diferentes atores sociais nos âmbitos ambiental, social e cultural dos territórios (ABRAMOVAY, 2009; SACHS, 2004; DOWBOR, 2002; LÉLÉ, 1991).

Para atender essa amplitude de ação,será preciso que o desenvolvimento envolva a territorialização com sustentabilidade por meio de arranjos de convivência social que envolvesse a eliminação das principais fontes de privação de liberdade humana, como a pobreza extrema, falta de oportunidade econômica, exclusão social, intolerância, tirania e/ou repressão do Estado (SEN, 2010).Aterrritorialização pode ser entendida como uma forma de pensar as realidades locais com algo além de uma demarcação de um espaço físico, como um espaço de relações entre indivíduos dos diferentes setores da sociedade.

Sob esta perspectiva, há mais de uma década, a Carta da Terra (2000, p. 15) "reconhece que os objetivos de proteção ecológica, erradicação da pobreza, desenvolvimento econômico equitativo, respeito aos direitos humanos, democracia e paz são interdependentes e indivisíveis" devem ser alcançados para a preservação da vida humana. O objetivo do desenvolvimento em um determinado território precisa também estar relacionado com a "avaliação das liberdades reais desfrutadas pelas pessoas" (SEN, 2010, p. 77). É preciso levar em conta que a liberdade, como a entende Sen (2010), inclui, de forma inter-relacionada, alguns fenômenos como "facilidades econômicas, liberdades políticas, oportunidades sociais, garantias de transparência e segurança protetora" (SEN, 2010, p. 77).

Considerando que se trata de algo que vai além de uma demarcação de um espaço físico, a gestão territorial tem uma relação direta com a ampliação da participação populara partir de estruturas de governança, por envolver, também, um espaço de relações entre indivíduos dos diferentes setores da sociedade. A necessidade de estruturas de governança que possibilitem associar a necessidade de uma ampla participação popularestá relacionada à promoção da equidade social, com a participação das comunidades por meio da governança participativa e 
promoção de atividades econômicas, de forma a fortalecer e contribuir para a melhoria desta e outras dimensões da vida e da convivência no território.

Nos processos de desenvolvimento, as estratégias de governo e governança social são temas importantesno contexto da descentralização, principalmente quando tratamos de territórios periféricos. A implementação, obstáculos e consequências dessa descentralização são temas que perpassam áreas de conhecimento desde a ciência política até a gestão social. O debate da descentralização não pode ser entendido assim, como um fenômeno monolítico na medida em que envolve transformações politicas, econômicas e sociais. Portanto, está vinculado a uma série de interesses e atores (BYDLOWSKI; LEFÈVRE; PEREIRA, 2011; MATOS, 2011; ELSTUB, 2010).

Nesse contexto, à medida que a descentralização alcança efetivo poder nas instituições locais, poderia incentivar a participação popular, uma vez que viabilizaria a proximidade entre gestores e cidadãos, além de permitir o aparecimento de formas mais efetivas de controle sobre a agenda e as ações de governo (ARRETCHE, 1996). O cenário político se veria diante de novos grupos que se envolvem nessa dinâmica. Atores esses representantes e possuidores de diferenciados graus de organização e interesses, que começaram a fazer parte da vida política. No entanto, no cenário atual, atores tradicionais vinculados ao Estado desenvolvimentista burocracia, sindicatos e grupos profissionais - vem perdendo a legitimidade na América Latina e a capacidade de controlar os recursos e a agenda pública.

Nessa análise podemos citar alguns aspectos centrais indicados por Sen (2010) sobre a relação entre a liberdade política e os direitos democráticos: (i) a capacidade 'direta' de participação política e social; (ii) a capacidade 'instrumental' de ouvir de outras pessoas reinvindicações com foco político; e (iii) o 'papel construtivo' para compreender as necessidades econômicas em contextos sociais.

A transformação pode estar presente na forma como os atores sociais se encontram para construir novas ordens sociais locais e estabelecer estratégias de convencimento de determinados grupos a cooperar reciprocamente (FLIGSTEIN, 2007).Dessa forma, no processo sócio-histórico dos territórios, a construção do poder local pode provocar disputa pelos arranjos de governança em espaços nos quais se organiza a vida dos cidadãos (SPINK, 2001).

Ciência e Sustentabilidade - CeS / Juazeiro do Norte v. 2, n. 2, p. 28-50, jul/dez 2016 
Para ser eficaz, essa forma de participação requer mudanças dentro da própria administração (BRUGUÉ, 2009), sendo os caminhos para essa trajetória, muitas vezes, divergentes e complexos. Conforme com Fligstein (2007), a busca de habilidade social exige identificar quem são os principais atores coletivos, e como eles podem criar uma coalizão política em torno de sua nova 'identidade'. Em busca de um processo de construção de significado para influenciar políticas públicas (OSPINA; SHALL, 2001), tende-se à possibilidade de provocaruma forma de liderança como mecanismo que faça as coisas acontecerem num contexto de colaboração (VANGEN;HUXHAM, 2003).

Nesse processo de interações sociais dos diferentes atores, uma pergunta desponta, "como obter novas formas de parceria entre o Estado, a sociedade civil e o mundo dos negócios, de forma a fortalecer e realizar todo o potencial das iniciativas locais e das ações civis?" (SACHS, 1997, p. 223).A ação intersetorial se apresenta como alternativa e denota benefícios como o aumento da eficiência da intervenção operacional das organizações, apresentando aquisição de habilidades e competências, superação de lacunas, resolução de necessidades, garantia de sustentabilidade das ações e uso potencializado dos recursos.

No entanto, em um cenário em que as oportunidades de governo, sociedade civil e empresas atuem juntos e contribuam para a promoção do desenvolvimento, os desafios comuns às efetivas parcerias surgem como dificultadores desse processo. Isto porque essas parcerias são relações onde duas ou mais partes, com objetivos compatíveis, entram em acordo para realizar um projeto em comunhão, e para que tenha êxito, as partes envolvidas têm que ser beneficiadas. As parcerias intersetoriais nos territórios e a ampliaçãodo princípio participativo pode, então, contribuir para a construção uma cultura mais democrática (MILANI, 2008).

Por isso, a ação das organizações da sociedade civil não poderia configurarse como uma instância substitutiva das políticas públicas, apesar de muitas vezes iniciar sua ação em contextos nos quais o Estado e/ou a empresa estão pouco atuantes ou não respondem adequadamente às demandas da sociedade (DOWBOR, 2002).Na busca do desenvolvimento sustentável, não será possívelmais trabalhar na superfície dos problemas sociais e, muito menos, realizar intervenções 
com metodologias que possam criar, nas comunidades, a dependência de projetos sociais desenvolvidos, apenas pelo setor privado ou, isoladamente, pelo governo ou sociedade civil (FISCHER, 2002; TEODÓSIO, 2008).

É preciso ampliar a forma de convivência e colaboração dos atores nos territórios como princípio fundamental para o alcance do desenvolvimento sustentável, conectando parcerias intersetoriais e processos de liderança e criando mecanismos de uma estratégia participativa de relacionamento entre diferentes grupos sociais que se encontram no território (CLARK; FULL, 2010). É preciso ainda, analisar a convergência de interesses que possam alimentar os motivos que estejam influenciando essa estratégia de colaboração participativa no território (ARMISTEAD; PETTIGREW; AVES, 2007), compreendida aqui como uma dinâmica na qual o cidadão se envolve na decisão e assume o compromisso da execução das ações, de forma contínua e corresponsável com aqueles que também participaram do processo. Dessa forma o desenvolvimento sustentável poderáalcançado, quando permitir a sua apropriação pelas comunidades, sendo que a mobilização dessas capacidades seria vital para, efetivamente, gerar um desenvolvimento participativo (SACHS; LOPES; DOWBOR, 2010).

As parcerias intersetoriais podem assim, tornar o desenvolvimento de comunidades mais sustentável, na medida em que permitir que haja uma governança participativa, como reflexo de um acordo mútuo com valores e prioridades que sejam capazes de promover o desenvolvimento humano e criar um senso de propriedade e contribuição de todos os que dele participam.

\section{CONSIDERAÇÕES FINAIS}

Esse estudo buscou compreender os aspectos teóricos que compreendem a prática do desenvolvimento sustentável.Para tanto, optou-se por construir a discussão através da ótica de governança. Nessa abordagem, destacam-se como a participação popular e as parcerias intersetoriais podem proporcionar ganhos de diferentes magnitudes e sentidos para os diferentes atores envolvidos (VANGEN; HUXHAM, 2003).

Dificuldades existem e as realizações através de parcerias intersetoriais, na prática, ganham cada vez mais importância como um elemento político para a 
governança compartilhada e para o desenvolvimento endógeno de um determinado território (SELSKY; PARKER, 2005). Entretanto, o engajamento entre os múltiplos atores da sociedade precisa ser reconstruído continuamente e de forma bastante atenta e crítica, a fim de evitar que a própria participação popular leve a um aprofundamento do centralismo, tecnocracia, desigualdade social e política e de dinâmicas pouco horizontais e democráticas nos processos de desenvolvimento sustentável.

Para que as formas de participação não fiquem esvaziadas de conteúdo ou mesmo, e principalmente, de sentido, a concepção de políticas em prol do desenvolvimento das comunidades não pode prescindir apenas de uma análise da realidade social e do impacto dos projetos existentes. É preciso que se reconheça a exclusão territorial de contingentes populacionais. É necessário também que se estimule o comprometimento da população, que precisa se mobilizar e estar predisposta ao debate político das realidades a partir de relações efetivamente horizontais e não de ações tuteladas e justificadas exatamente pela suposta fragilidade das pessoas e grupos sociais em vulnerabilidade social (TATAGIBA, 2002; AVRITZER ;RECAMÁN; VENTURI, 2004; GUZA, 2007).

Os estudos sobre a dinâmica de governança na promoção do desenvolvimento sustentável se constituem em uma importante agenda de investigação contemporânea, que pode e deve contar com as contribuições de longa data dos estudos latino-americanos sobre participação popular, tema tão caro a acadêmicos e ativistas da América Latina. Estudos de realidades específicas, comparando diferentes territórios da América Latina entre si e com outras partes do mundo, bem como investigações a partir de dados mais amplos podem aprofundar a urgente e necessária compreensão da construção de processos de governança compartilhada na promoção do desenvolvimento sustentável. Tais esforços não se resumem à importância teórica e acadêmica, mas também podem trazer novas luzes para as reflexões que sempre envolvem todos aqueles comprometidos com a sustentabilidade, a democracia e a equidade social, característica muito marcante, novamente, do pensamento latino-americano. 


\section{REFERÊNCIAS}

ABRAMOVAY, R. Responsabilidade socioambiental: as empresas no meio ambiente, o meio ambiente nas empresas. In: J. E. Veiga (Org.) Economia socioambiental. (no prelo). 2009.

ALVES, M. A. O conceito de sociedade civil: em busca de uma repolitização. Organizações \& Sociedade, Salvador, v.11, p.141-154, 2006.

ARMISTEAD, C., PETTIGREW, P.;AVES, S. Exploring leadership in multi-sectoral partnerships. Leadership,

[2007].Disponívelem<http://lea.sagepub.com/cgi/content/abstract/3/2/211>. Acesso em 10 nov 2013.

ARRETCHE, M. Mitos da descentralização: mais democracia e eficiência nas políticas públicas. Revista Brasileira de Ciências Sociais, v.31,n.11,p. 44-66,1996.

AVRITZER, L;RECAMÁN, M.;VENTURI, G. O associativismo na cidade de São Paulo, in Leonardo Avritzer (org.).O associativismo em São Paulo, São Paulo, Editora da Unesp, 2004.

BRASIL. Ministério do Meio Ambiente (2000). Carta da terra. Recuperado em 20 de outubro. [2013]. Disponível em

$<$ http://www.mma.gov.br/estruturas/agenda21/ arquivos/carta terra.pdf.> Acesso em 22 nov. 2016.

BROSE, M. et al. Metodologia participativa: uma introdução a 29 instrumentos. Porto Alegre: Tomo Editorial (Org), 2001.

BRUGUÉ, Q. Una administración que habla es una administración que piensa: de la gestión pública a la administración deliberativa. In: Perez, I. C., Martin, F. L., Gayán, S. C.; Valenzuela, T. G. Participación ciudadanapara una administración deliberativa. Aragón: Gobierno de Aragón, p.55-72. 2009.

BYDLOWSKI,C. R., LEFÈVRE, A.M. C., PEREIRA, I.M.T.B. Promoção da saúde e a formação cidadã: a percepção do professor sobre cidadania. Revista Ciência e Saúde Coletiva, 2011.

CANÇADO, A. C.; Tavares, B. \& Valdir, R. D. Gestão social e governança territorial: interseções e especificidades teórico-práticas. Revista Brasileira de Gestão e

Desenvolvimento Regional, v. 9, n.3, p.313-353, 2013. 
CARRION, R. M.;BAUER, M. Governança: Vocabulário polissêmico de fácil uso político partidário. In: V Encontro Nacional de Pesquisadores em Gestão Social. Florianópolis, SC, Brasil, p.1-19, 2011.

CAVALCANTE, P. Descentralização de politicas publicas sob a ótica neoinstitucional: uma revisão bibliográfica. Revista de Administração Pública, Rio de Janeiro, nov, 2011.

CLARKE, A.;FULL, M. Collaborative strategic management: strategy formulation and implementation by multi-organizational cross-sector social partnerships. Journal of Business Ethics, v.94, v.1, p. 85-10, 2010.

CORNWALL, A. Locating Citizen Participation, IDS Bulletin, v.33, n.2, p. 49-58, 2002.

COSTA, M. A. N. Strategic corporate social responsibility in public policies in Brazil: the case of health. In BRASA - Tulane University, New Orleans, Louisiana, IX, p. 2729, 2008.

DOWBOR, L. et al. A Comunidade inteligente: visitando as experiências de gestão local. In: Silvio Caccia-Bava, Veronika Paulics, Peter Spink (Org). Novos contornos da gestão local: conceitos em construção. Pólis Programa Gestão Pública e Cidadania, Escola de Administração de Empresas de São Paulo, Fundação Getúlio Vargas, p.33-51, 2002.

ELSTUB,S. The thrid generation of deliberative democracy. Political Studies Review Sheffield. n.8, p.291-307, 2010.

FISCHER, R. M., FEDATO, M. C. L.;BELASCO, P. F. Sustentabilidade sócioambiental de alianças estratégicas intersetoriais: um estudo de caso sobre comunidades extrativistas na região da Amazônia. In: Conferencia Regional de América Latina y del Caribe de ISTR. Universidad Ricardo Palma, Peru, p.1-27, 2005.

FISCHER, T. Poderes locais, desenvolvimento e gestão: introdução a uma agenda. In: T. Fischer (Org.). Gestão do desenvolvimento e poderes locais: marcos teóricos e avaliações. Salvador: Casa da Qualidade, 2002.

FLISGSTEIN, N. Habilidade social e a teoria dos campos. Revista de Administração de Empresas, v. 47, n.2, p. 61-80,2007.

GOHN, M. da G.Movimentos sociais no início do século XXI: antigos e novos atores sociais. Vozes, Petrópolis/RJ, 2003. 
GURZA, L. AProtagonistas na sociedade civil: redes e centralidades de organizações civis em São Paulo. Dados, p. 465-498, 2007.

LÉLÉ, S. M. Sustainable development: a critical review. World Development, v.6, n. 19 , p. 607-621, 1991.

LÉVESQUE, B., HARRISSON, D., FONTAN, J. M. ;KLEIN, J. L. The Quebec system of social innovation: a focused analysis on the local development field. Finisterra, $\mathrm{v}$. 47, n. 94, p.9-28, 2012.

LÜCHMANN, L. H. H. Associações, participação e representação: combinações e tensões. Revista Lua Nova, n. 84, 2011 (no prelo).

LÜCHMANN, L. H. H. A democracia deliberativa: sociedade civil, esfera pública e institucionalidade. Cadernos de pesquisa, 2002.

MATOS, A. R. I. A importância da participação cidadã nas políticas de saúde: o caso da reestruturação dos serviços de saúde materno-infantil em Portugal. Revista de saúde e sociedade. São Paulo, v.20,n.3, p.604-616, 2011.

MILANI, Carlos R. S. Mitos construídos acerca da "participação" no âmbito dacooperação internacional para o desenvolvimento: um olhar a partir daexperiência brasileira recente. In: CARRIZO, Luis e GALLICCHIO, Enrique.Desarrollo Local y Gobernanza, Enfoques Transdisciplinarios.

Montevidéu:CLAEH/UNESCO/Cooperación Andino de Fomento, p. 125-135, 2006.

NAJAM, A.The Four-C's of Third Sector- Government Relations Cooperation, Confrontation, Complementarity, and Co-optation. NoProfit Management \& Leadership, Summer, v. 10, n. 4, , 2000.

OSPINA, S.;SCHALL, E. Leadership (re)constructed: how lens matters. Paper for Presentation at Appam Research Conference. Washington, DC, United State, p.121, 2001.

PETTIGREW, P. J.. Power, conflicts and resolutions: a change agent's perspective on conducting action research within a multi-organizational partnership. Systemi Practice and Action Research, v.16, p.6, p. 375-391, 2003.

PIMENTEL, T. D.;PIMENTEL, M. P. C. Governança territorial como estratégia de gestão social do desenvolvimento. In: Encontro Nacional de Pesquisadores em Gestão Social, Vitória, Espírito Santo, 2010. 
SACHS, I. Desenvolvimento includente, sustentável, sustentado. Rio de Janeiro: Garamond, 2004.

SACHS, I., LOPES, C., DOWBOR, L. Crises e oportunidades em tempos de mudança. Fórum Social Mundial Temático, 2010. Disponível

emwww.criseoportunidade.worpress.com. Acesso em 13 de set. 2013.

SANTOS. B. S. Critica da governação neoliberal: o fórum social mundial como legitimidade cosmopolita subalterna. Revista Critica de Ciencias Sociais. Coimbra, n.72, p. 7-44.7, 2005.

SELSKY, J. W.; PARKER, B. Cross-sector partnerships to address social issues: challenges to theory and practice. Journal of Management, 2005. Disponível em http://jom.sagepub.com/cgi/content/abstract/31/6/849. Acesso em 10 de setembro, 2013.

SEN, A. Desenvolvimento como liberdade. São Paulo: Companhia de Bolso, 2010.

SPINK, P. O Lugar do Lugar na Análise Organizacional. Revista de Administração Contemporânea (Edição Especial), 2001.

TATAGIBA, L. Os conselhos gestores e a democratização das políticas públicas no Brasil. In: Dagnino, E. (org.). Sociedade civil e espaços públicos no Brasil. São Paulo: Paz e Terra,2002.

TENÓRIO F.G. Cidadania e desenvolvimento local: casos brasileiros. In: COSCreso Internacional del CLAD sobre la Reforma del Estado y de la Administración Pública. Madrid, España, IX, 2004.

TEODÓSIO, A. S. S. Parcerias tri-setoriais na esfera pública: implicações, impasses e perspectivas acerca da provisão de políticas sociais em três experiências. Tese (Doutorado em Administração) - Faculdade de Administração, Fundação Getúlio Vargas, São Paulo, 2008.

VANGEN, S.; HUXHAM, C. Enacting leadership for collaborative advantage: dilemmas of ideology and pragmatism in the activities of partnership managers. British Journal of Management, v.14, p. 61-76, 2003.

WHITE, S. C. Depoliticising development the uses and abuses os participation. In Development, NGO'S, and Civil Society. Ed Oxfam GB, 2000. 